\title{
Inconsciente: matriz freudiana do conceito lacaniano de sujeito
}

Unconscious: Freudian version of Lacanian concept of subject

Inconsciente: versión freudiana del concepto lacaniano de sujeto

\author{
Adriane Freitas Barroso* \\ Ilka Franco Ferrari ${ }^{* *}$
}

\begin{abstract}
Resumo
$\mathrm{O}$ artigo aborda o inconsciente freudiano como subversão do cogito cartesiano, premissa da ciência moderna, centrado na razão e na ideia de unidade. Toma também o conceito de inconsciente como a definição freudiana que, posteriormente, é trabalhada por Lacan em seu retorno a Freud e dá origem à concepção de sujeito em psicanálise. Se o inconsciente é a descoberta freudiana, podemos atribuir a Lacan a construção formal do conceito de sujeito, a partir das pegadas deixadas por Freud no percurso de sua descoberta princeps.
\end{abstract}

Palavras-chave: Inconsciente. Sujeito. Psicanálise. Pulsão.

\begin{abstract}
The article discusses the Freudian concept $f$ unconscious as a subversion of the Cartesian cogito, standard of modern science, based on the ideas of unity and reason. It also takes the concept of the unconscious as the definition that is visited by Lacan in his return to Freud and gives rise to the concept of subject in psychoanalysis. If the unconscious is the Freudian discovery, we can assign to Lacan the construction of the formal concept of the subject, from the footprints left by Freud in the course of his main discovery.
\end{abstract}

Keywords: Unconscious. Subject. Psychoanalysis. Drive.

\section{Resumen}

El artículo analiza el inconsciente freudiano como subversión del cogito cartesiano, la asunción de la ciencia moderna, la razón y centrado en la

\footnotetext{
Doutoranda em Psicologia pela PUC Minas, com graduação em Psicologia pela PUC Minas (2004) e em Comunicação Social pela UFMG (2001), psicanalista.E-mail: adrianebr@uol.com.br.

** Pós-doutorada em Psicologia pela Universidade de Barcelona (Espanha), doutora em Psicologia pelo Programa de Clínica y Aplicaciones del Psicoanális, na Universidade de Barcelona, professora adjunta e coordenadora do Programa de Pósgraduação em Psicologia da Pontifícia Universidade Católica de Minas Gerais.
} 
idea de la unidad. También lleva el concepto de lo inconsciente como la definición de Freud, que posteriormente es elaborado por Lacan en su retorno a Freud y da lugar al concepto de sujeto en el psicoanálisis. Si el inconsciente es el descubrimiento freudiano, podemos asignar a Lacan la construcción del concepto formal del sujeto, a partir de las huellas dejadas por Freud en el curso de la princeps su descubrimiento.

Palabras clave: Inconscientes. Sujeto. Psicoanálisis. Pulsión.

Em 1895, Freud (1996l) publica seu "Projeto para uma psicologia científica", trazendo concepções embrionárias sobre a construção de um aparato psíquico que seria alicerce de um novo campo de saber. A metapsicologia freudiana é, assim, fundada como o coração da teoria psicanalítica, propondo um mais além da consciência e estabelecendo-se, inicialmente, na análise dos processos psíquicos conforme três coordenadas: dinâmica, tópica e econômica.

Localizar casos, avaliar pontos fortes, calcular investimentos e gastos: é esse o triplo imperativo da explicação metapsicológica. É no nó desses três processos que toma forma "o inconsciente" como objeto metapsicológico. (Assoun, 2002, p. 27. Tradução nossa). ${ }^{1}$

Inicialmente, portanto, Freud aproxima a psicanálise de uma ciência da natureza, apoiando-a em modelos que definem forças e quantidades. Seu interesse recaía também sobre a relação do organismo com o meio, explicitando que a obra freudiana teve raízes biológicas e físicas e seguiu, em seus primórdios, o discurso cientificista da época e os ideais mecanicistas (Lacan, 2008), próprios de sua formação médica: "a intenção é prover uma psicologia que seja ciência natural” (Freud, 19961, p. 338).

Foi a chegada da Modernidade que criou condições para pensar o ser humano de maneira individual, para além das instituiçōes. O século XVIII trouxe o Renascimento, impondo o impacto da Reforma sobre a crença religiosa: a fé se tornou atividade reflexiva, abalando explicações místicas sobre o mundo, e a razão passou a ser o fundamento do conhecimento (Bezerra Júnior, 1989). Não se falava ainda em singularidade, mas em igualdade, universalização do direito ao pensamento, consciência e racionalidade, próprias do sujeito cartesiano.

Localizar las instancias, evaluar las fuerzas, calcular las inversiones y los gastos: tal es el triple imperativo de la explicación metapsicológica. Es en el nudo de esos tres procesos donde cobra forma "lo inconsciente" como objeto metapsicológico. 
O que garantiu o terreno propício para o surgimento da subjetividade veio mais tarde: o anseio por liberdade que brotou na realidade moderna. Esse pilar exigiu outro momento, no século XIX, que enfatizasse a importância da diferença, de forma que os indivíduos não fossem abarcados apenas coletivamente, mas também um a um.

É, portanto, "entre dois" o lugar da teoria psicanalítica: representante do mundo moderno, herdeira do cogito cartesiano, mas transgressora de alguns de seus aspectos mais caros, pois pioneira em sua maneira de abordar o sujeito, ultrapassando o coletivo. Se o princípio do discurso do mestre é acreditar-se unívoco, o passo dado pela psicanálise foi fazer aparecer um sujeito que não o é. Em lugar de um "ou não penso ou não sou", diz Lacan (1992, p. 96), surge um "ali onde penso não me reconheço, não sou - é o inconsciente. Ali onde sou, é mais do que evidente que me perco".

A psicanálise só se funda porque a ciência a precede. Contudo se estabelece justamente como ruptura com o saber científico preexistente. Ela não faz continuidade com saber algum, apesar de estar ligada, como condição de possibilidade, ao conjunto de saberes sobre o homem que se forma desde as alteraçôes vividas pelo mundo a partir da modernidade (Garcia-Roza, 2001).

\section{Raízes biológicas de um conceito incipiente}

Em linhas gerais, o "Projeto para uma psicologia científica" (Freud, 19961) funda a concepção de um aparelho (ou aparato) psíquico; na definição de Assoun (2002), aparato é um objeto ou uma maquinaria composta por peças destinadas a produzir certo resultado. A ideia pode ser aplicada tanto a uma maquinaria artificial, como uma prótese, quanto a um sistema anatômico, como um conjunto de órgãos que participam de uma mesma função (Assoun, 2002). Freud pensou o aparelho psíquico como classes de neurônios que trabalhariam em prol de uma mesma tendência: a descarga de excitações que $\mathrm{o}$ atingem, pondo-o em movimento constante.

$\mathrm{O}$ autor assumia, nesse primeiro momento, que o funcionamento psíquico seguia o princípio da inércia, que determina que o organismo seja dotado de movimentos reflexos para fugir de estímulos externos. Do ponto de vista biológico, a estrutura do ser vivo seria dominada por um processo de homeostase, de isolamento do mundo exterior, tendendo à manutenção de um estado constante.

O circuito psíquico, contudo, traz um complicador que o impede de se defender usando apenas reflexos: ele recebe também do interior do organismo, 
dos quais é impossível fugir. Para que cessem, são necessárias certas condiçōes, obtidas desde ações específicas (spezifische Aktion) (Freud, 19961), executadas à custa de uma quantidade mínima de excitação. A necessidade de que esse mínimo esteja presente e viabilize tais açôes impede que o princípio de inércia funcione pela via da descarga completa. É a partir daí que Freud (1996l) postula a tendência do aparelho psíquico a reduzir tanto quanto possível sua quantidade, mantendo, porém, sempre um mínimo que atenda às exigências da vida.

De forma a garantir esse acúmulo quantitativo mínimo necessário, a passagem da excitação pelo aparelho tem de ser dificultada: Freud (19961) hipotetiza a existência de uma resistência entre neurônios que atua como barreira, opondo-se à descarga. Em um grupo, essa barreira permite a passagem da excitação sem sofrer alterações, enquanto em outro ela é impermeável, permanecendo modificada após ser atravessada. A diferença de resistência é o que distingue essas duas classes de neurônios, nomeados por Freud (1996l) de $\varphi$ (phi) e $\psi(p s i)$, respectivamente.

Os neurônios $\varphi$ seriam perceptuais, situados na periferia do aparelho psíquico, em contato com o mundo externo e recebendo, por isso, maiores excitações. Contra essas quantidades maiores, as barreiras de contato mostram-se proporcionalmente fracas, daí sua permeabilidade. Os neurônios $\psi$, mnêmicos, por sua vez, só recebem excitações do mundo interno ou vindas indiretamente por meio de $\varphi$, o que resulta em quantidades recebidas mais baixas, contra as quais suas barreiras oferecem resistência significativa, tornando-as impermeáveis.

O local por onde uma excitação atravessa os neurônios impermeáveis $(\psi)$ torna aquele ponto da barreira mais capaz de condução, o que Freud nomeia facilitação (Bahnung) (Freud, 1996l). Uma trilha se abre, ampliando a passagem da quantidade. Esses caminhos abertos guardam a história do percurso da excitação e definem, no "Projeto", a memória (Freud, 19961).

Nem só de quantidades, porém, constrói-se o aparelho psíquico. Além de $\varphi$ e $\psi$, há uma terceira categoria de neurônios responsável pela qualidade, determinante da ampla gama de sensaçóes com as quais lida o ser humano. Esses neurônios são chamados de $\omega$ (Freud, 19961) e recebem cargas ainda mais reduzidas, captando não excitações em si, mas períodos de $\psi$, e definindo a partir deles a qualidade. Para que isso ocorra, Lacan (2008) explica que algo no circuito sensação-motricidade deve interessar o sistema $\psi$ e ser, então, retroativamente percebido para que $\omega$ possa 
produzir um registro. Seria natural pensar que, estando ligado a $\psi$ e fora da superfície do aparelho, $\omega$ fosse também impermeável, mas não é o que ocorre. Como responde a outros grupos de neurônios, é preciso que esteja aberto à mutabilidade, à transitoriedade, voltando rapidamente a seu estado anterior, o que explica o fato de seus neurônios não guardarem traço (Garcia-Roza, 2001).

É em $\omega$, que reside a noção de consciência no "Projeto" (Freud, 19961). A qualidade tornar-se-ia consciente apenas em certas condições, uma vez que os órgãos dos sentidos, entradas do aparelho psíquico, não apenas barram quantidades, mas definem os períodos autorizados a passar por $\varphi$ e $\psi$ para serem lidos, posteriormente, em $\omega$. A consciência seria o lado subjetivo dos processos físicos do aparelho, deixando de ser característica de toda realidade psíquica e passando a atributo de apenas uma parte dela, desde que satisfeitas determinadas condições (Simanke \& Caropreso, 2005). Processos psíquicos seriam continuamente produzidos, mas apenas alguns seriam conscientes, os demais nunca chegando à consciência.

Essa concepção traz uma alteração significativa na noção sujeito da razão, tendo acesso a informações objetivas sobre si e o mundo pelos sentidos, elaboradas pelo pensamento. Para a psicanálise, o exterior é subjetivado, chegando ao aparelho psíquico de forma descontínua e selecionada: "O homem lida com peças escolhidas da realidade" (Lacan, 2008, p. 62).

Porque não há correlação direta entre realidade e sua leitura psíquica, temos aí uma fonte de enganos. A descarga do aparelho traz experiências de satisfação que deixam um registro, um traço mnêmico, reativado quando surge um novo estado de tensão semelhante. Esse engano produz, mesmo com o objeto ausente, algo análogo à sua percepção, fazendo o infans ${ }^{2}$ reagir como se estivesse em sua presença: uma alucinação. Lacan (1985) explica que é como se uma imagem fosse impressa no aparelho psíquico, como uma placa sensível que, quando ativada, reproduz a imagem original. Para impedir o mal-estar decorrente desse engano, um grupo de neurônios $\psi$ diferenciar-seia para dificultar a passagem de excitação quando se trata de um objeto apenas alucinado, exercendo função inibidora, de defesa. É esse grupo especial que Freud (1996l) chama, no "Projeto", de eu. ${ }^{3}$ Ele é responsável pelo teste de

\footnotetext{
Termo em latim que pode ser livremente traduzido por "aquele que ainda não fala". Lacan nomeia assim o que antecede o advento do sujeito da linguagem.

Adotamos, neste trabalho, a proposta dos tradutores para a língua portuguesa dos Seminários de Jacques Lacan de empregar pronomes da própria língua para definir o que Freud chama, em alemão, de ich, uber-ich e es, nomeando-os, respectivamente, eu, supereu e isso. Segundo nota dos tradutores (Lacan, 1985, p. 408), "nada justifica o emprego dos termos latinos de id, ego e superego, introduzidos pela tradução inglesa". As transcrições de trechos das obras consultadas e citadas na pesquisa, contudo, trazem, como é de praxe, as nomeaçóes originalmente utilizadas por seus autores.
} 
realidade, localizando-se no sistema $\psi$, "[...] no âmago do aparelho psíquico" (Lacan, 1985, p. 184). Sua leitura não é feita por acesso direto, mas mediada pelas impressões da experiência registradas no aparelho.

Esses registros passam por sucessivas reorganizações, diz Freud um pouco mais tarde, em sua "Carta 52" (Freud, 1996e). Os estímulos sensoriais que incidem sobre a periferia do sistema nervoso4 sofreriam rearranjos em seu percurso da medula ao córtex. Em cada sistema de neurônios, seriam escavados 5 traços, resultando em camadas superpostas que alteram continuamente a informação inicial e impedem a certeza que pode ser obtida pela razão.

$\mathrm{Na}$ "Carta 52", a organização do aparelho psíquico é revista por Freud (1996e), guardando muitas semelhanças com os sistemas definidos pelo "Projeto".

a) a excitação que chega ao aparelho encontraria, primeiramente, o sistema W (wahrnehmungen, percepçôes), análogo ao sistema $\varphi$ do "Projeto" (Freud, 1996l). Trata-se da camada responsável pelas percepções, porta de entrada da excitação, que não registra traço de memória porque um sistema não pode ser responsável por receber estímulos e, ao mesmo tempo, modificar-se, já que o estímulo precisa encontrá-lo intacto;

b) os primeiros registros e, consequentemente, o trabalho de memória e permanência só vão ser realizados em um segundo momento, na camada Wz (wahrnehmungen zeichen, indicações de percepção);

c) após $\mathrm{Wz}$, a excitação atingiria Ub (unbewusstsein), o inconsciente, que registra conceitos, e passaria ao pré-consciente $(\mathrm{Vb}$, vorbewusstsein), onde se dá a transcrição de palavras. Logo, "inconsciente" deixa de ser apenas um adjetivo para designar um sistema do aparelho psíquico, noção sistemática que amplia a anterior, meramente descritiva;

d) somente uma associação entre conceito e palavra, entre traços deixados em $\mathrm{Ub}$ e $\mathrm{Vb}$, permitiria a passagem à consciência (Bew, bewusstsein), que não registra traço por conter neurônios semelhantes a W (e próximos ao conceito de neurônios $\omega$ do "Projeto"). A consciência seria resultado que dependeria da harmonia entre conceito e sua respectiva palavra, da equivalência perfeita os esses dois registros.

\footnotetext{
4 Vale lembrar que Freud ainda acreditava estar tratando de neurônios e não do aparato psíquico como lugar abstrato.

Essa "escavação" assemelha-se à técnica da escrita cuneiforme, nomeação dada ao tipo de escrita feita com o auxílio de objetos em formato de cunha, formando um sulco no material que lhe serve de apoio.
} 
Figura 1. Esquema do aparelho psíquico apresentado na "Carta 52".

$$
\begin{array}{ccccc} 
& \text { I } & \text { II } & \text { III } & \\
\text { W } & \text { Wz } & \text { Ub } & \text { Vb } & \text { Bew }
\end{array}
$$

Fonte: Freud (1996e)

Freud estabelece um aparelho que abarca outros processos que não os cognitivos. A excitação partiria dos órgãos responsáveis por estímulos sensoriais e atravessaria diversas etapas de memória, sofrendo retranscrições em cada uma delas até chegar, se atendidas todas as exigências, à consciência, cada vez mais afastada de uma objetividade (Caropreso, 2006). A razão é traída por esse funcionamento e o registro da realidade sofre interferência dos rearranjos mnêmicos.

No texto "A interpretação dos sonhos" (Freud, 1996b), as camadas do aparelho psíquico aparecem dispostas não mais por ordem espacial, mas temporal, de acesso. Estímulos internos e externos percorreriam seu caminho em direção a inervações, definindo o aparelho como portando uma extremidade sensorial e outra motora, tal como o aparelho reflexo. Mais uma vez, os traços mnêmicos surgem reescritos ao longo dos sistemas, podendo ou não se tornar conscientes. É possível que falhas impeçam a associação entre conceito e palavra e, consequentemente, a passagem do conteúdo à consciência. Era essa a concepção de recalque que Freud tinha à época: a interceptação (sempre de natureza sexual) do caminho de registros, de forma a evitar o desprazer (Freud, 1996e). A consciência passa a ser mero efeito do inconsciente (Garcia-Roza, 2001), alterando significativamente a concepção cartesiana.

\section{Para além do organismo, a pulsão... e o sujeito}

Quantidade e níveis de excitação são o que atraem Freud na tentativa inicial de explicar o aparelho psíquico, bem à maneira das ciências naturais e da mecânica. No entanto, o que escapa à medida impõe à psicanálise uma mudança metodológica.

A pulsão é a resposta evidente de Freud ao que ultrapassa o biológico e o mecânico. Trata-se de um novo objeto colocado pela psicanálise no mundo, comprovável apenas por observação indireta, quando se faz ressoar na clínica psicanalítica. Ela é definida como:

[...] Conceito situado na fronteira entre o mental e o somático, como o representante psíquico dos estímulos que se originam dentro do organismo e 
alcançam a mente, como uma medida da exigência feita à mente no sentido de trabalhar em consequência de sua ligação com o corpo. (Freud, 1996c, p. 127).

Entende-se como pulsão o estímulo que garante uma circulação constante no aparelho psíquico, desmontando qualquer tendência à inércia. $\mathrm{O}$ desequilíbrio tensional exige sempre a execução de um ato, que demanda alguma energia ligada, não livre. Não seria possível, então, eliminar definitivamente a tensão do aparelho psíquico, o que faz com que a satisfação trazida pela descarga seja invariavelmente parcial, deixando um resto. Esse constante relançamento é força motriz ininterrupta do aparelho, que exige infinitamente mais, "furo" permanente no corpo erógeno, introduzindo a dimensão da causa. Esse corpo sexual, que surge apoiado nas funções vitais, mas transcende a anatomia e torna-se independente delas, é o suporte do aparato psíquico. A realidade psíquica é sexual, ultrapassando a satisfação da necessidade e a conservação da vida biológica.

A primeira e mais vital das atividades da criança - mamar no seio materno (ou em seus substitutos) - há de tê-la familiarizado com esse prazer. Diríamos que os lábios da criança comportaram-se como uma zona erógena, e a estimulação pelo fluxo cálido de leite foi sem dúvida a origem da sensação prazerosa. A princípio, a satisfação da zona erógena deve ter-se associado com a necessidade de alimento. A atividade sexual apoia-se primeiramente numa das funçôes que servem à preservação da vida, e só depois se torna independente delas (Freud, 1996o, p. 171).

A pulsão é dotada de uma força, um fator motor que tem como fim a supressão do estado de excitação. Para realizar a descarga necessária a esse fim, ela visa a um objeto, que é tão variável quanto possível. Se o instinto traz padrões fixos de funcionamento, o objeto da pulsão é eleito ao longo da trajetória singular de cada ser humano (Freud, 1996o).

Em direção a esse objeto, a pulsão faz um curso eferente e, em seguida, um resto retorna à sua fonte, o eu, em um curso aferente, promovendo um movimento pendular. Nessa segunda etapa, a trajetória pulsional converte o autor da ação também em alvo. É o que demonstra, por exemplo, o masoquismo, em que o "autor intelectual" da ação é também seu destinatário (Freud, 19960), deixando evidente que agente e sujeito não são equivalentes na lógica psíquica.

Se há sempre um resto, não estamos falando de um objeto harmonioso e satisfatório, "[...] que funda o homem numa realidade adequada, na realidade que prova a maturidade - o famoso objeto genital" (Lacan, 1995, p. 13). O objeto que encontramos é sempre uma substituição, um reencontro parcial, que faz apenas alusão àquele envolvido nas primeiras satisfações do infans: "Uma 
nostalgia liga o sujeito ao objeto perdido, através da qual se exerce todo o esforço da busca" (LACAN, 1995, p. 13). Essa insatisfação impossível de ser saciada faz apelo à repetição, ao que, do aparelho psíquico, não cessa de ser relançado. Por isso, dizer do objeto em psicanálise é sempre dizer de sua insuficiência, do hiato que ele deixa e onde se aloja o desejo.

Se a pulsão pode ser satisfeita sem ter atingido aquilo que, em relação a uma totalização biológica da função, seria a satisfação ao seu fim de reprodução, é que ela é pulsão parcial, e que seu alvo não é outra coisa senão esse retorno em circuito (Lacan, 1998c, p. 170).

Nas entrelinhas da relação com o objeto, Lacan localiza em Freud o sujeito. No momento em que o movimento da pulsão se fecha, após ir em direção ao objeto e retornar à fonte, algo é produzido como saldo ou efeito. Não se trata de mera reversão de ativo a passivo, mas do nascimento de um elemento inédito, em um terceiro tempo: o retorno em circuito dá origem, diz Freud, a "ein neues Subjeckt"6 (Lacan, 1998c, p. 169).

O sujeito em Lacan tem várias roupagens: está no intervalo significante, está nas linhas do desejo, está na linguagem. Aqui, contudo, Lacan encontra o sujeito em Freud articulado a um fluxo de tensão, sem qualquer materialidade: "O objeto da pulsão deve ser situado no nível que chamei metaforicamente uma subjetivação acéfala, uma subjetivação sem sujeito" (Lacan, 1998c, p. 174). Por "sem sujeito", podemos entender a ausência de uma localização objetiva, de consistência, aparecendo e desaparecendo na mesma rapidez com que a tensão escoa do eu ao objeto e retorna. Percebe-se, também aqui, um movimento semelhante ao que veremos com detalhes em Lacan: a presença de qualquer coisa que possa ser chamada de sujeito, já em Freud, é cada vez mais fluida e aos lampejos.

Figura 2. Curso circular da pulsão

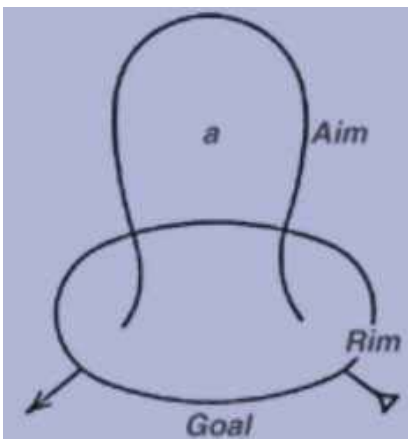

Fonte: Lacan (1998c, p. 170)

Expressão alemã que significa "um novo sujeito" (tradução nossa). 


\section{Há sentido no aparelho psíquico}

Freud se preocupou muito tentando reabsorver a psicanálise às ciências da natureza. Preocupou-se por isso desde seu primeiro trabalho, inédito, que só foi conhecido depois de sua morte, o Projeto para uma Psicologia Científica, e essa ambição se manifesta também em suas tentativas de Metapsicologia: reabsorver a psicanálise às ciências da natureza. De fato, porém, sua metapsicologia nunca foi mais do que uma análise da estrutura radical da linguagem, o que podemos chamar de uma lógica do significante (Miller, 2002, p. 13).

A quantidade não encerra o que Freud tem a dizer sobre o funcionamento do aparelho psíquico, e a importância do sentido vai assumindo o primeiro plano de sua obra. Em torno dele (como evidenciam os chistes, o ato falho, os sonhos e as produções do inconsciente de modo geral), giram as concepçóes freudianas até 1920, ano em que a teoria da pulsão de morte introduz um mais além do sentido e da interpretação na experiência analítica.

Em "A concepção psicanalítica da perturbação psicogênica da visão", a vida psíquica é definida por Freud (1996a) como resultado de um jogo de forças, e a oposição ativa de uma parte a outra determinaria o recalque. O sintoma, diz o autor, viria em substituição a algo que a consciência, para evitar o sofrimento, teria mantido afastada de seu campo. Sua fixidez e constância seria consequência do fato de que esse afastamento não faz cessar a existência e a atividade do material excluído, que continua a agir no aparelho psíquico, mesmo sob efeito da censura.

Para estabelecer as bases desse conflito pulsional, Freud lança mão da dicotomia entre pulsões do eu, que visam à autopreservação, e pulsões sexuais, voltadas para o mundo externo. Uma vez que essas duas categorias teriam os mesmos órgãos à sua disposição e que "não é fácil para alguém servir a dois senhores ao mesmo tempo" (Freud, 1996a, p. 225), uma cisão acontece: quanto mais estreita a relação de um órgão com um tipo de pulsão, mais o outro tipo se retrai. Na cegueira histérica, por exemplo, o eu perde seu domínio sobre o olho, que ficaria à disposição da pulsão sexual recalcada: "É como se o recalque houvesse sido exagerado pelo eu, como se tivesse despejado a criança com a água do banho [...]" (Freud, 1996a, p. 226). O eu recalca, de maneira bemsucedida, o representante pulsional, mas deixa de dominar o órgão, pois a pulsão sexual invade a função orgânica.

Ao incidir sobre o organismo, o sexual promove "alterações tóxicas" 
(Freud, 1996a, p. 227) em seu funcionamento. A toxicidade da pulsão se liga a seu caráter de repetição, como Freud explicita no texto "Recordar, repetir e elaborar" (Freud, 1996m).

Decompõe-se, assim, a noção de eu como sede da verdade. $\mathrm{O}$ cogito freudiano revela-o, ao contrário, como lugar de ocultação, afetado pelo inconsciente. É com essa descoberta que Freud, segundo ele próprio, estabelece o terceiro golpe narcísico sofrido pela humanidade: além de a Terra não ser o centro do universo e de os homens não serem seres à parte da evolução da espécie, mas descendentes dos animais, "o ego não é o senhor de sua própria casa” (Freud, 1996p, p. 153). No momento em que a consciência ganha lugar de efeito do inconsciente, subverte-se a lógica cartesiana: “[...] esse sujeito do 'eu penso' revela o que é: o ser de uma queda. [...] o 'logo', traço da causa, separa originalmente o 'eu sou' da existência do 'eu sou' do sentido" (Lacan, 2003b, p. 211).

Com o conceito de narcisismo, Freud (1996n) define o eu como um dos objetos de investimento da pulsão. Ele surge pelo endereçamento orientado das pulsões a um ponto específico, após um período inicial de desorientação por conta da ausência de unificação da imagem do corpo. Há, quando desse surgimento, um desinteresse pelo mundo externo, que marca o narcisismo primário. Paulatinamente, contudo, o aparelho psíquico deixa de funcionar como sistema fechado e volta-se para a realidade, dando lugar ao narcisismo secundário, quando o investimento objetal já é possível, embora haja sempre retorno de uma parcela da pulsão ao eu, um resto que mantém o aparelho em movimento.

As pulsões do eu, portanto, não se distinguem em sua origem das pulsões objetais, apenas tomam o eu como objeto. Com o narcisismo, toda a concepção freudiana do campo pulsional passa a ter um único substrato, a libido, de cunho sexual (Freud, 1996n).

Há, contudo, algo de muito próprio ao funcionamento psíquico e que permanece estranho ao eu. Freud (1996j, p. 242) utiliza o termo unheimlich, vocábulo alemão que, entre seus significados, exibe um que é idêntico a seu oposto (heimlich): "Por um lado, significa o que é familiar e agradável e, por outro, o que está oculto e se mantém fora da vista”. O unheimlich faz parte do grande giro que Freud realiza em sua teoria ao reconhecer no aparelho psíquico algo que escapa à lógica de manutenção de uma quantidade mínima de excitação.

Falamos, a partir daí, da compulsão à repetição, “[...] poderosa o bastante para prevalecer sobre o princípio do prazer, emprestando 
a determinados aspectos da mente o seu caráter demoníaco" (Freud, 1996j, p. 256). Como Lacan, mais tarde, deparar-se-á com um ponto de virada que leva a seu terceiro e último ensino, tem-se aqui um giro na teoria freudiana, do princípio do prazer a algo que escapa a ele. Ambos os movimentos, freudiano e lacaniano, apontam para uma transposição do simbólico ao real. Até a pulsão de morte, a instância real aparecia em Freud ainda nas entrelinhas; o sonho da injeção de Irma, em 1900, traz elementos que demonstram que Freud estava atento a algo que escapava ao sentido, mas não era ainda capaz de teorizá-lo (Freud, 1996b). É com a pulsão de morte que algo na clínica psicanalítica se organiza para além do que é interpretável, colocando a psicanálise diante do enigma do que fazer com o que não se cura.

\section{Para além do princípio do prazer}

Uma dimensão existe para além das homeostases do eu, uma outra corrente, uma outra necessidade, que carece distinguir no seu plano. Essa compulsão a voltar de algo que foi excluído do sujeito, ou que nele nunca entrou, o Verdrangt ${ }^{7}$ o recalcado, não podemos fazê-lo entrar pelo princípio do prazer. Se o eu como tal se orienta e se reconhece, é que existe um para além do ego, um inconsciente, um sujeito que fala, desconhecido pelo sujeito. Logo, carece supor um outro princípio (Lacan, 1985, p. 217).

A descarga do aparelho psíquico pode ocorrer de duas formas, segundo Freud (1996b): na primeira, a energia escoa livremente; enquanto, na segunda, ela encontra-se ordenada, definindo um fluxo articulado.

A esses dois modos de funcionamento corresponderiam, respectivamente, o princípio do prazer e o princípio da realidade. Enquanto se supunha que o princípio do prazer regia todo o aparelho psíquico, eles eram tomados como instâncias opostas: a busca pelo prazer traria um negativo, que visaria à evitação da dor e do desprazer, garantindo tolerância temporária aos obstáculos no mundo externo que exigem caminhos mais longos para a satisfação.

Em 1920, contudo, Freud (1996d) estabelece uma virada em seu ensino ao formalizar um funcionamento para além do princípio do prazer. Princípios do prazer e da realidade passam, então, a ser tomados como correlativos dialéticos (Rudge, 1998), avesso e continuidade, à maneira da Banda de Moebius. ${ }^{8}$ Ambos tratam do processo secundário, energia pulsional ligada,

\footnotetext{
Termo alemão utilizado por Freud para o que, em português, traduz-se por recalcado.

Espaço topológico obtido pela colagem das duas extremidades de uma fita após se efetuar nela uma meia-volta. O uso dessa figura no ensino de Lacan é extenso e será abordado mais à frente neste trabalho.
} 
orientada em direção ao eu e circulante no aparelho psíquico, garantindo sua manutenção, que "[...] o combate não termine por falta de combatentes" (Lacan, 1985, p. 112). Na experiência clínica, o princípio do prazer/realidade faz existir um fator inercial que tende à perpetuação do sintoma, trazendo a resistência. A associação livre parece saturar-se, rodando em torno de um núcleo central que remete apenas a si próprio. O ensino lacaniano vai tomá-la, mais tarde, como repetição atrelada à cadeia significante, ao que, pelo que resta impossível de dizer, insiste e retorna ao mesmo lugar sucessivas vezes.

Já o processo primário, mais elementar e determinado pela descatexia, pela energia livre, ficaria restrito à forma de funcionamento da pulsão de morte. Ultrapassando a repetição atrelada à linguagem, há a exigência pulsional que visa a uma satisfação absoluta, estabelecendo a compulsão à repetição. Lacan (1985) utiliza a metáfora do homem como máquina, posto em funcionamento incessante por algo que incide de fora do simbólico. Buscar o nível mais baixo de tensão diz da busca pelo equilíbrio do sistema, mas também do "puro e simples mais baixo" (Lacan, 1985, p. 107), retorno a algo anterior à vida: a compulsão à repetição visa à morte.

A concepção dualista de pulsões objetais e do eu, suspensas quando o eu é tomado como objeto de investimento, transfere-se para a oposição entre pulsões de vida e de morte. As pulsões de vida buscariam garantir a normalidade do caminho para a morte ao preservar o organismo de fatores externos nocivos, operando contra o propósito das pulsões de morte, que se fazem escutar pela repetição não temperada pelo princípio do prazer, dando origem a uma intensidade muito maior de satisfação.

O sujeito pode ser inferido, em uma leitura lacaniana desse momento do texto de Freud, como função dessa pulsão acéfala, que visa exclusivamente à satisfação. A repetição como função simbólica seria já a tentativa de evitar o encontro com o real que escapa ao sentido, chamado por Lacan (1998c) de "tiquê". Tiquê é o que está além da insistência dos signos comandada pelo princípio do prazer, é o que está excluído da cadeia significante e que se produz ao acaso, nonsense que força o deslocamento para um novo sentido. $\mathrm{O}$ real da tiquê interrompe o funcionamento do que Lacan (1998c) nomeia "autômaton", seriação automática do significante no inconsciente, gerada pela representação faltosa que exige que o sujeito volte a buscar o objeto perdido, tornando a não o encontrar (Fink, 1997). Com Lacan, podemos pensar em dois tipos de real: um ordenado, atrelado ao simbólico e ao recalque secundário, e 
outro ligado ao trauma, ao recalque primário, inassimilável.

Afastando-se da razão, Freud aproxima-se cada vez mais de algo que aflora aos lampejos, como acontecimento pontual e fugaz. Não o inconsciente como algo mais profundo ou obscuro que a consciência, mas como uma instância portadora de uma lógica própria, inédita, que se faz ver em intervalos. Desembaraçamo-nos, assim, do paralelismo consciente/inconsciente, diz Vieira (1999), para pensarmos em formas de funcionamento distintas, em que nenhuma é mais verdadeira ou primitiva. Trata-se de duas cenas. A Outra cena de que fala Freud (1996g) só tem sentido se articulada à cena, em um jogo de cena sobre cena que faz surgir a impossibilidade do significante, de que mais tarde se ocupa Lacan, de significar a si mesmo, remetendo-nos então à ancoragem no real. O que é próprio do inconsciente é a habilidade de passar de uma cena a outra, como mostram as formações do inconsciente. O real, ao mesmo tempo em que está para além da linguagem, tem nela sua morada, o que embaça a fronteira entre dizível e indizível para dar lugar ao dito e, nele, a algo que insiste em não se dizer e, assim, fala sem parar (Vieira, 1999).

É justamente por se dar conta que nenhuma das duas cadeias, consciente e inconsciente, estão aptas a produzir o sujeito se tomadas isoladamente que Lacan subverte a leitura clássica freudiana sobre o sintoma e a clínica psicanalítica (vale lembrar que o próprio Freud vai percebendo a insuficiência de sua leitura inicial, conforme a pulsão de morte lança nova luz sobre seu edifício teórico).

Assim, compreende-se por que tanto é falso atribuir o desenlace analítico à conscientização quanto é inútil espantar-se que aconteça de ela não ter essa virtude. Não se trata de passar de um patamar inconsciente, mergulhado na obscuridade, para o patamar consciente, sede da clareza, através de sabe-se lá que misterioso elevador (Lacan, 2003a, p. 146).

A frase freudiana "wo es war, soll ich werden" (Freud, 1996h), traduzida para o inglês por Strachey ${ }^{9}$ como "where the id was, there the ego shall be", ${ }^{10}$ ganha nova leitura sob o prisma da pulsão de morte. Lacan atenta para o fato de Freud não dizer "das Es" nem "das Ich", como fazia habitualmente para designar essas instâncias, "[...] e isso,

\footnotetext{
Psicanalista britânico, responsável, com sua esposa, Alix Strachey, pela tradução da obra de Freud para o inglês e editor geral da Standard edition of the complete psychological works of Sigmund Freud (Gay, 1989).

${ }^{10} \mathrm{Na}$ tradução para o português da edição usada neste trabalho, a frase que consta é "onde estava o id, ali estará o ego" (Freud, 1996h, p. 84).
} 
considerando o rigor inflexível de seu estilo, dá ao emprego delas na frase uma ênfase particular" (Lacan, 1998b, p. 418). Não seria de substâncias que o Pai da Psicanálise estaria falando, mas da exigência de assunção de uma verdade desconhecida pelo eu, compatível com o advento do sujeito. Tal leitura impõe outra tradução: "Lá onde isso estava, lá, como sujeito, devo (eu) advir" (Lacan, 1998a, p. 878). O sujeito cartesiano que "estava ali" é atingido pela repetição d'Isso: "Isso sou", diria o sujeito freudiano (Cabas, 2009).

Lacan se debruça sobre o sujeito ao longo de todo o seu ensino. Ele encontra na frase de Freud um sentido até então obscurecido, não apenas pelos deslizes de tradução ou por mera discussão linguística, mas por um entrave conceitual que exigiu o avanço da teoria para ser elucidado.

\section{Referências}

Assoun, P-L (2002). La metapsicologia. Buenos Aires: Siglo XXI Editores.

Bezerra Jr., B. (1989). Subjetividade moderna e o campo da psicanálise. In: J. Birman et al. Freud 50 anos depois. (pp. 219-239). Rio de Janeiro: RelumeDumará.

Cabas, A. C. (2009). O sujeito na psicanálise de Freud a Lacan: da questão do sujeito ao sujeito em questão. Rio de Janeiro: Jorge Zahar.

Caropreso, F. (2006). A relação entre a memória, a percepção e a consciência na metapsicologia freudiana. Revista Adverbum, 1 (1), 12-22.

Fink, B. (1997). A causa real da repetição. In: Richard Feldstein et al. Para ler o Seminário 11 de Lacan: os quatro conceitos fundamentais da psicanálise. (pp. 239-245). Rio de Janeiro: Jorge Zahar.

Freud, S. (1996a). A concepção psicanalítica da perturbação psicogênica da visão. In: S. Freud. Edição standard das obras psicológicas completas de Sigmund Freud (Jaime Salomão e Orizon Carneiro Muniz, Trad., Vol. 11, pp. 218227). Rio de Janeiro: Imago. (Trabalho original publicado em 1910.)

Freud, S. (1996b). A interpretação dos sonhos II. In: S. Freud. Edição standard das obras psicológicas completas de Sigmund Freud (Jaime Salomão e Orizon Carneiro Muniz, Trad., Vol. 5, pp. 564-579). Rio de Janeiro: Imago. (Trabalho original publicado em 1900.) 
Freud, S. (1996c). A pulsão e suas vicissitudes. In: S. Freud. Edição standard das obras psicológicas completas de Sigmund Freud (Jaime Salomão e Orizon Carneiro Muniz, Trad., Vol. 14, pp. 116-123). Rio de Janeiro: Imago. (Trabalho original publicado em 1915a.)

Freud, S. (1996d). Além do princípio do prazer. In: S. Freud. Edição standard das obras psicológicas completas de Sigmund Freud (Jaime Salomão e Orizon Carneiro Muniz, Trad., Vol. 18, pp. 13-78). Rio de Janeiro: Imago. (Trabalho original publicado em 1920.)

Freud, S. (1996e). Carta 52. In: S. Freud. Edição standard das obras psicológicas completas de Sigmund Freud (Jaime Salomão e Orizon Carneiro Muniz, Trad., Vol. 1, pp. 281-287). Rio de Janeiro: Imago. (Trabalho original publicado em 1896.)

Freud, S. (1996f). Inibição, sintoma e angústia. In: S. Freud. Edição standard das obras psicológicas completas de Sigmund Freud (Jaime Salomão e Orizon Carneiro Muniz, Trad., Vol. 20, pp. 81-171). Rio de Janeiro: Imago. (Trabalho original publicado em 1926.)

Freud, S. (1996g). Lembranças encobridoras. In: S. Freud. Edição standard das obras psicológicas completas de Sigmund Freud (Jaime Salomão e Orizon Carneiro Muniz, Trad., Vol. 3, pp. 284-306). Rio de Janeiro: Imago. (Trabalho original publicado em 1899.)

Freud, S. (1996h). Novas conferências introdutórias sobre psicanálise. Conferência XXI: a dissecção da personalidade psíquica. In: S. Freud. Edição standard das obras psicológicas completas de Sigmund Freud (Jaime Salomão e Orizon Carneiro Muniz, Trad., Vol. 18, pp. 13-78). Rio de Janeiro: Imago. (Trabalho original publicado em 1933.)

Freud, S. (1996i). O chiste e suas relações com o inconsciente. In: S. Freud. Edição standard das obras psicológicas completas de Sigmund Freud (Jaime Salomão e Orizon Carneiro Muniz, Trad., Vol. 8, pp. 13-78). Rio de Janeiro: Imago. (Trabalho original publicado em 1905b.)

Freud, S. (1996j). O estranho. In: S. Freud. Ediçãostandard das obras psicológicas completas de Sigmund Freud (Jaime Salomão e Orizon Carneiro Muniz, Trad., Vol. 17, pp. 234-276). Rio de Janeiro: Imago. (Trabalho original publicado em 1919.) 
Freud, S. (1996k). O inconsciente. In: S. Freud. Edição standard das obras psicológicas completas de Sigmund Freud (Jaime Salomão e Orizon Carneiro Muniz, Trad., Vol. 14, pp. 165-224). Rio de Janeiro: Imago. (Trabalho original publicado em 1915c.)

Freud, S. (19961). Projeto para uma psicologia científica. In: S. Freud. Edição standard das obras psicológicas completas de Sigmund Freud (Jaime Salomão e Orizon Carneiro Muniz, Trad., Vol. 1, pp. 335-397). Rio de Janeiro: Imago. (Trabalho original publicado em 1895.)

Freud, S. (1996m). Recordar, repetir e elaborar (novas recomendações sobre a técnica da psicanálise II). In: S. Freud. Edição standard das obras psicológicas completas de Sigmund Freud (Jaime Salomão e Orizon Carneiro Muniz, Trad., Vol. 12, pp. 159-171). Rio de Janeiro: Imago. (Trabalho original publicado em 1914a.)

Freud, S. (1996n). Sobre o narcisismo: uma introdução. In: S. Freud. Edição standard das obras psicológicas completas de Sigmund Freud (Jaime Salomão e Orizon Carneiro Muniz, Trad., Vol. 14, pp. 77-108). Rio de Janeiro: Imago. (Trabalho original publicado em 1914b.)

Freud, S. (1996o). Três ensaios sobre a teoria da sexualidade. In: S. Freud. Edição standard das obras psicológicas completas de Sigmund Freud (Jaime Salomão e Orizon Carneiro Muniz, Trad., Vol. 7, pp. 119-209). Rio de Janeiro: Imago. (Trabalho original publicado em 1905a.)

Freud, S. (1996p). Uma dificuldade no caminho da psicanálise. In: S. Freud. Edição standard das obras psicológicas completas de Sigmund Freud (Jaime Salomão e Orizon Carneiro Muniz, Trad., Vol. 17, pp. 144-153). Rio de Janeiro: Imago. (Trabalho original publicado em 1917.)

Garcia-Roza, L. F. (2001). Freud e o inconsciente. Rio de Janeiro: Jorge Zahar.

Gay, P. (1989). Freud: uma vida para nosso tempo. São Paulo: Companhia das Letras.

Lacan, J. (1985). O seminário, livro 2: o Eu na teoria de Freud e na técnica da psicanálise. Rio de Janeiro: Imago. (Trabalho original publicado em 19541955.)

Lacan, J. (1992). O seminário, livro 17: o avesso da psicanálise. Rio de Janeiro: Imago. (Trabalho original publicado em 1969-1970.) 
Lacan, J. (1995). O seminário, livro 4: a relação de objeto. Rio de Janeiro: Imago. (Trabalho original publicado em 1956-1957.)

Lacan, J. (1998a). A ciência e a verdade. In: Escritos (pp. 855-892). Rio de Janeiro: Imago. (Trabalho original publicado em 1966.)

Lacan, J. (1998b). A coisa freudiana ou Sentido do retorno a Freud em psicanálise. In: Escritos (pp. 402-437). Rio de Janeiro: Imago. (Trabalho original publicado em 1955.)

Lacan, J. (1998c). O seminário, livro 11: os quatro conceitos fundamentais em psicanálise. Rio de Janeiro: Imago. (Trabalho original publicado em 1964.)

Lacan, J. (2003a). Discurso de Roma. In: J. Lacan. Outros escritos (pp. 402437). Rio de Janeiro: Imago. (Trabalho original publicado em 1953.)

Lacan, J. (2003b). Respostas a estudantes de filosofia. In: J. Lacan. Outros escritos (pp. 210-218). Rio de Janeiro: Imago. (Trabalho original publicado em 1966.)

Lacan, J. (2008). O seminário, livro 7: a ética da psicanálise. Rio de Janeiro: Imago. (Trabalho original publicado em 1959-1960.)

Miller, J-A. (2002). Percurso de Lacan: uma introdução. Rio de Janeiro: Jorge Zahar.

Rudge, A. M. (1998). Pulsão e linguagem: esboço de uma concepção psicanalítica do ato. Rio de Janeiro.

Simanke, R. T. \& Caropreso, F. S. (2005). O conceito de consciência no Projeto de uma psicologia de Freud e suas implicações metapsicológicas. Trans/Form/Ação. 28 (1), 85-108.

Vieira, M. A (1999). Sobre o Seminário V de Jacques Lacan e sua teoria clínica da significação (ou o chiste e sua relação com as formações do inconsciente). In: M. B Motta \& S. Jimenez. O desejo é o diabo. (pp. 87-100). Rio de Janeiro: Contracapa. 